\title{
Regression of cardiac abnormalities after replacement therapy in Addison's disease
}

\author{
F Fallo, C Betterle, S Budano ${ }^{1}$, M Lupia ${ }^{1}$, M Boscaro and N Sonino \\ Division of Endocrinology, Institute of Semeiotica Medica, University of Padova, Padova, Italy and ${ }^{1}$ Cardiology Unit, Padova Civic Hospital, \\ Padova, Italy \\ (Correspondence should be addressed to F Fallo, Division of Endocrinology, Institute of Semeiotica Medica, University of Padova, Via Ospedale 105, \\ 35128 Padova, Italy)
}

\begin{abstract}
Objective: To evaluate by echocardiography the cardiac structure and function in patients with primary adrenocortical insufficiency.

Design and Methods: Two-dimensionally guided M-mode echocardiograms and spectral Doppler studies were performed in seven consecutive patients with newly diagnosed autoimmune primary adrenal failure before and 4-8 months after an adequate regimen of steroid substitution. Echocardiographic parameters were also studied in ten healthy controls.

Results: In the cases with untreated Addison's disease, both left ventricular end-systolic and enddiastolic dimensions were significantly reduced in comparison with those in controls $(P<0.01)$. Four patients had echocardiographic signs of mitral valve prolapse (MVP) at the anterior leaflet, with no evidence of mitral regurgitation by Doppler echocardiography. Systolic clicks characteristic of MVP were present on auscultation in two of these cases. Left ventricular chamber size normalized, i.e. significantly increased $(P<0.01)$, and both echocardiographic and physical signs of MVP resolved after steroid substitution in all patients. All other echocardiographic indices were normal before and after treatment.

Conclusions: Patients with untreated Addison's disease have cardiac abnormalities which regress after steroid substitution. A valvular-ventricular disproportion due to the hypovolemic state could explain these findings.
\end{abstract}

European Journal of Endocrinology 140 425-428

\section{Introduction}

Glucocorticoids and mineralocorticoids play an important role in the regulation of systemic hemodynamics in man (1). Cortisol acts either directly or indirectly, by potentiation of vasoactive factors, on peripheral vessels and heart tissue (2). Aldosterone, in addition to having its volume-related modulatory effect on blood pressure, has been recently indicated as a direct regulator of cardiac extracellular matrix and collagen deposition (3). An excess of these hormones is associated with considerable cardiac abnormalities, mainly including myocardial hypertrophy and dysfunction (4, 5), whereas little is known when production of adrenal steroids is impaired. The purpose of this study was to evaluate by echocardiography the cardiac structure and function in patients with primary adrenal insufficiency, before and during steroid replacement therapy.

\section{Materials and methods}

Seven consecutive patients (mean age $29.7 \pm 1.3$ years, six females and one male), with newly diagnosed autoimmune primary adrenal insufficiency, were prospectively evaluated by echocardiography before and 48 months after an adequate regimen of steroid replacement therapy. The diagnosis rested on typical clinical manifestations and laboratory data: high serum potassium values, low levels of plasma cortisol uninfluenced by the administration of adrenocorticotropin (ACTH) (1-24) (250 $\mathrm{g}$; Synacthen; Ciba, Basel, Switzerland) as an i.v. bolus, elevated levels of endogenous ACTH, and low plasma aldosterone levels in the face of high plasma renin activity (PRA). Duration of disease (mean $3.6 \pm 1$, range $2-8$ months) was obtained from careful investigation of the patient's history, including early symptoms. Maintenance treatment consisted of orally administered cortisone acetate (37.5-50 mg/day; $25 \mathrm{mg}$ at $0830 \mathrm{~h}$ and $12.5-25 \mathrm{mg}$ at $1830 \mathrm{~h})$, and $9 \alpha$-fluorohydrocortisone $(0.05-0.1 \mathrm{mg} /$ day at $0830 \mathrm{~h})$. Adequacy of treatment was judged on clinical well-being, normal serum electrolytes, and PRA in the normal range (6). ACTH levels were also evaluated. No patients had symptoms attributable to mitral prolapse or a history of endocarditis or anorexia nervosa. None had symptoms of Marfan's syndrome, 
chest wall deformities, thickened redundant mitral leaflets by echocardiography, or had family members known to have mitral prolapse. A group of ten sex-, ageand body mass index (BMI)-matched control subjects, free of any evidence of adrenal and cardiac disease, was also studied (control).

Two-dimensionally derived M-mode echocardiograms and spectral Doppler echocardiographic studies were performed with a Hewlett-Packard model 500 system (Palo Alto, CA, USA) with a 2.5 and/or $3.5 \mathrm{MHz}$ phased array transducers echocardiographic machine. Subjects were examined in the morning in a quiet room in the left lateral decubitus position. All studies were recorded on videotape and stored for later review by two echocardiographers (SB and $\mathrm{ML}$ ) who were blinded regarding the subject's name, date on which the study was performed, and possible treatment. According to the American Society of Echocardiography recommendations using leading edge methodology (7), the following echocardiographic measurements were determined: left atrial dimension measured at end-ventricular systole; left ventricular end-systolic dimension (LVDS); left ventricular end-diastolic dimension (LVDD); interventricular septal thickness; left ventricular posterior wall thickness; fractional shortening of the left ventricle determined as the percentage difference between systolic and diastolic internal diameter. Left ventricular mass was indexed for body surface area. Intra-observer variability was determined using a set of M-mode registrations of the left ventricle in 20 normal subjects, each examined three times. Measurements were obtained for at least three consecutive cardiac cycles and results were averaged. In our laboratory, coefficients of variation were within $8 \%$ for all parameters. For the analysis of mitral valve motion, mitral valve was imaged from parasternal long axis, parasternal short axis and apical four chambers. In accordance with the definition of Devereux et al. (8), mitral valve prolapse (MVP) was diagnosed if: (1) superior billowing of either leaflet (beyond the valve ring) across the plane of the mitral anulus was seen on parasternal long-axis view of the two-dimensional examination, (2) mitral regurgitation was documented by Doppler echocardiography or (3) more than $2 \mathrm{~mm}$ displacement of either mitral leaflet posterior to the line connecting the valve's closure and opening points was seen on M-mode echocardiography. If none of the three criteria was present, mitral valve was described as normal. Auscultatory findings characteristic of MVP included an apical mid to late systolic murmur or apical mid to late systolic clicks. Timeinterval for echocardiographic control after replacement therapy corresponded to that required to obtain the clinical and biochemical balance of patients.

Plasma concentrations of ACTH (normal values: 4$22 \mathrm{pmol} / \mathrm{l}$ ), PRA (normal values: $1-4.5 \mathrm{ng} / \mathrm{ml}$ per $3 \mathrm{~h}$ ), aldosterone (normal values: $80-500 \mathrm{pmol} / \mathrm{l}$ ), and cortisol (normal values: $138-580 \mathrm{nmol} / \mathrm{l}$ ) were measured using commercially available RIA kits, as previously reported in detail (9). In all treated patients the samples for hormone blood measurements were obtained $3 \mathrm{~h}$ after the morning steroid dose. Student's $t$-test for paired or unpaired samples, and $\chi^{2}$ test corrected with the continuity, as appropriate, were used. Results are expressed as mean \pm S.E.M. $P<0.05$ was considered to indicate a statistically significant difference.

The study was approved by the local research Ethics Committee and fully explained to all subjects who gave informed written consent.

\section{Results}

Patients with untreated Addison's disease had in baseline conditions of hyperkalemia $(5.5 \pm 0.1 \mathrm{mmol} /$ l) and hyponatremia $(129.4 \pm 2.1 \mathrm{mmol} / \mathrm{l})$, low levels of plasma cortisol unchanged after exogenous ACTH administration $(59.3 \pm 9.2$ to $54.4 \pm 14.1 \mathrm{nmol} / \mathrm{l})$, low plasma aldosterone $(64.2 \pm 11.1 \mathrm{pmol} / \mathrm{l})$, high endogenous ACTH $(126.2 \pm 32.6 \mathrm{pmol} / \mathrm{l})$ and PRA (58.6 \pm $9.4 \mathrm{ng} / \mathrm{ml}$ per $3 \mathrm{~h})$. At the time of cardiac study after replacement therapy, serum potassium $(4.3 \pm 0.1 \mathrm{mmol} / \mathrm{l})$, serum sodium $(140.4 \pm 0.8 \mathrm{mmol} / \mathrm{l})$, ACTH $(18.4 \pm$ $2.5 \mathrm{pmol} / \mathrm{l})$ and PRA $(3.5 \pm 0.2 \mathrm{ng} / \mathrm{ml}$ per $3 \mathrm{~h})$ were all normal; no change in BMI was observed (from $22.9 \pm 1.8$ to $23.4 \pm 2.1 \mathrm{~kg} / \mathrm{m}^{2}$, not significant).

Hemodynamic and echocardiographic parameters of Addisonian patients and normal controls are summarized in Table 1 . Blood pressure showed a significant increase $(P<0.01)$ after replacement therapy. Untreated Addisonian patients had both LVDS and LVDD significantly smaller than those of controls $(P<0.01)$, and at the lower limits of normality range inferred from international studies (10). In four patients echocardiographic signs of MVP were also observed. No evidence of mitral regurgitation documented by Doppler echocardiography was observed. Systolic clicks characteristic of MVP were present on auscultation in two of these cases. Left ventricular chamber dimension normalized, i.e. significantly increased $(P<0.01)$, and both echocardiographic and physical signs of MVP resolved after steroid substitution in all patients. All other echocardiographic indices were normal before and after replacement therapy.

\section{Discussion}

Prominent cardiovascular features in chronic adrenal insufficiency are historically known as low cardiac output and decreased vascular tone associated with hyponatremia and relative hypovolemia (11). In addition to low blood pressure, a loss of circadian rhythm of blood pressure has also been recently described (12). To our knowledge, scanty data derived from direct measurements of cardiac function are available in the literature. Short-time withdrawal of glucocorticoid replacement, maintaining mineralocorticoid therapy, has been shown to induce in patients with primary 
Table 1 Hemodynamic and echocardiographic findings in the study groups. All values are means \pm S.E.M.

\begin{tabular}{lccc}
\hline & \multicolumn{2}{c}{$\begin{array}{c}\text { Addisonian subjects } \\
(n=7)\end{array}$} & \\
\cline { 2 - 3 } & Baseline & After treatment & $\begin{array}{c}\text { Controls } \\
(n=10)\end{array}$ \\
\hline SBP $(\mathrm{mmHg})$ & $113.6 \pm 3.4$ & $130.0 \pm 3.4^{*}$ & $134.3 \pm 2.4 \#$ \\
DBP (mmH) & $71.4 \pm 2.6$ & $80.0 \pm 1.1^{*}$ & $82.3 \pm 1.2 \#$ \\
HR (b.p. min) & $83.1 \pm 2.5$ & $82.3 \pm 1.2$ & $79.6 \pm 2.5$ \\
LAD (mm) & $26.0 \pm 2.4$ & $27.9 \pm 1.9$ & $27.2 \pm 1.2$ \\
LVDS $(\mathrm{mm})$ & $23.0 \pm 1.0$ & $28.6 \pm 0.8^{*}$ & $27.8 \pm 1.0 \#$ \\
LVDD $(\mathrm{mm})$ & $34.1 \pm 1.1$ & $40.3 \pm 1.2^{*}$ & $43.2 \pm 1.5 \#$ \\
IVST $(\mathrm{mm})$ & $10.6 \pm 0.3$ & $10.5 \pm 0.5$ & $10.6 \pm 0.4$ \\
PWT $(\mathrm{mm})$ & $9.1 \pm 0.3$ & $9.6 \pm 0.3$ & $9.4 \pm 0.6$ \\
LVMI $\left(\mathrm{g} / \mathrm{m}^{2}\right)$ & $86.3 \pm 5.6$ & $89.9 \pm 14.5$ & $88.2 \pm 6.8$ \\
\% FS & $33.9 \pm 2.1$ & $33.4 \pm 1.1$ & $31.3 \pm 2.2$ \\
\hline
\end{tabular}

${ }^{*} P<0.01$ after treatment vs baseline; $\# P<0.01$ controls vs baseline. SBP, systolic blood pressure; DBP, diastolic blood pressure; HR, heart rate; LAD, left atrial dimension; LVDS, left ventricular end-systolic dimension; LVDD, left ventricular enddiastolic dimension; PWT, posterior wall thickness; IVST, interventricular septal thickness; LVMI, left ventricular mass index; FS, fractional shortening.

adrenocortical insufficiency an impairment of diastolic left ventricular function (13). This has been attributed to loss of $\beta_{2}$-adrenoceptor-permissive effect of glucocorticoids in the heart due to $\beta_{2}$-adrenoceptor density reduction, as shown in lymphocytes (13). A myocardial systolic dysfunction, assessed by echocardiography, has been described in patients with panhypopituitarism (14), but it has not been confirmed in other studies (15).

No clinical signs as well as echocardiographic features, i.e. abnormal fractional shortening, consistent with a decreased cardiac systolic contractility have been observed in our untreated Addisonian patients. A highoutput circulatory failure in acute adrenal insufficiency has been documented (16). At variance with these data, our findings may be in accordance with the slow onset of the disease, as derived from the medical history of our subjects, allowing hemodynamic compensation. Untreated Addison's disease is associated with cardiac changes characterized at echocardiography by small left ventricular chamber size and often MVP at the anterior leaflet. These findings appear to be similar to those described in other pathological conditions, such as Marfan syndrome, ostium secundum atrial septal defect and anorexia nervosa (8), where a disproportion between the mitral valve and left ventricular chamber has been indicated as the cause of cardiac alteration. Indeed, Lax et al. (17) have shown that short-terminduced mild dehydration in healthy females is able to induce echocardiographic signs of reduced ventricular volume and MVP, and that these changes resolve with rehydration. Our results indicate that untreated Addison's disease may represent another clinical condition in which reduction of left ventricular volume, due to systemic electrolyte and free water loss, may lead to MVP. This concept of volume-induced valvular-ventricular disproportion is further supported in our patients by complete regression of abnormal echocardiographic and physical features after normalization of sodiumvolume balance with adequate steroid replacement therapy, as reflected by normal biochemical and hormonal indices. Mitral regurgitation was not documented by Doppler echocardiography in any of the treated patients, suggesting that regurgitation was hemodynamically insignificant. According to the notion that left ventricular size is an important factor in determining MVP, our study suggests that echocardiography could be useful also in the short-term assessment of the effects of rehydration on heart function of patients with newly diagnosed Addison's disease. A high prevalence of cardiac failure in Addison's disease after long-term treatment, attributed to older age and/or pre-existing cardiac disease, has been found, but no details on mitral valve function were given (18). Usefulness of echocardiographic assessment in these patients remains to be defined.

\section{References}

1 Williams GH, Lilly LS \& Seely EW. The heart in endocrine and nutritional disorders. In Heart Disease. A Textbook of Cardiovascular Medicine, edn 5, ch 61, pp 1887-1913. Ed E Braunwald. Philadelphia: WB Saunders Company, 1997.

2 Fraser R, Davies DL \& Connell JMC. Hormones and hypertension. Clinical Endocrinology 198931 701-746.

3 Young M, Fullerton M, Dilley R \& Funder J. Mineralocorticoids, hypertension, and cardiac fibrosis. Journal of Clinical Investigation $1994932578-2583$.

4 Fallo F, Budano S, Sonino N, Muiesan ML, Agabiti-Rosei E \& Boscaro M Left ventricular structural characteristics in Cushing's syndrome. Journal of Human Hypertension 19948 509-513.

5 Rossi GP, Sacchetto A. Pavan E, Palatini P, Graniero GR, Canali C et al. Remodeling of the left ventricle in primary aldosteronism due to Conn's adenoma. Circulation 199795 1471-1478. 
6 Oelkers W, Diederich S \& Bahr V. Diagnosis and therapy surveillance in Addison's disease: rapid adrenocorticotropin (ACTH) test and measurement of plasma ACTH, renin activity, and aldosterone. Journal of Clinical Endocrinology and Metabolism $199275259-264$.

7 Sahn DJ, DeMaria A, Kisslo J \& Weyman A. The Committee on M-mode Standardization of the American Society of Echocardiography. Recommendations regarding quantitation in M-Mode echocardiography: results of a survey on echocardiographic measurements. Circulation 197858 1072-1083.

8 Devereux RB, Kramer-Fox R \& Kligfield P. Mitral valve prolapse: causes, clinical manifestatons, and management. Annals of Internal Medicine 1989111 305-317.

9 Boscaro M, Betterle C, Volpato M, Fallo F, Furmaniak J, Rees Smith $\mathrm{B}$ et al. Hormonal responses during various phases of autoimmune adrenal failure: no evidence for 21-hydroxylase enzyme activity inhibition in vivo. Journal of Clinical Endocrinology and Metabolism 199782 932-938.

10 Weyman AE. Principles and Practice of Echocardiography, edn 2, Philadelphia: Lea \& Febiger, 1994.

11 Burke CW. Adrenocortical insufficiency. Clinics in Endocrinology and Metabolism 198514 947-977.

12 Fallo F, Fanelli G, Betterle C, Boscaro M \& Sonino N. 24-h blood pressure profile in Addison's disease. American Journal of Hypertension 19947 1105-1109.
13 Allolio B, Ehses W, Steffen HM \& Muller R. Reduced lymphocyte $\beta 2$-adrenoceptor density and impaired diastolic left ventricular function in patients with glucocorticoid deficiency. Clinical Endocrinology 199440 769-775.

14 Shahi M, Beshyah M, Hackett D, Sharp PS, Johnston DG \& Foale RA. Myocardial dysfunction in treated adult hypopituitarism: a possible explanation for increased cardiovascular mortality. British Medical Journal 199267 92-96.

15 Dunne FP, Elliot P, Gammage MD, Stallard T, Ryan T, Sheppard MC et al. Cardiovascular function and glucocorticoid replacement in patients with hypopituitarism. Clinical Endocrinology 199543 623-629.

16 Dorin RI \& Kearns PJ. High output circulatory failure in acute adrenal insufficiency. Critical Care Medicine 198816 296-297.

17 Lax D, Eicher M \& Goldberg SJ. Mild dehydration induced echocardiographic signs of mitral valve prolapse in healthy females with prior normal cardiac findings. American Heart Journal 1992124 1533-1540.

18 Knowlton AI \& Baer L. Cardiac failure in Addison's disease. American Journal of Medicine 1983 74 828-836.

Received 7 August 1998

Accepted 11 January 1999 